\title{
SITUACIÓN DE VULNERABILIDAD EN LO EDUCATIVO DE LA POBLACIÓN ESCOLAR DE LA COMUNA 5 EN LA ZONA NORTE DE GUADALAJARA DE BUGA*
}

\author{
Jaime Aguilar Moreno*
}

\section{Resumen}

Este artículo analiza la situación de vulnerabilidad en lo educativo de la población en edad escolar de la comuna 5 en la zona norte de Guadalajara de Buga, siguiendo el enfoque de la vulnerabilidad, en especial los argumentos propuestos por Rubén Kaztman y Gustavo Busso, y la perspectiva de las capacidades desarrollado por Martha Nussbaum. En la parte descriptiva se utilizan las estadísticas sobre homicidios y violencia intrafamiliar, así como los registros sobre matrícula en educación preescolar, primaria, básica secundaria y media, al igual que la cobertura educativa en la ciudad. Además, se incorporan los resultados de la encuesta aplicada a una muestra de docentes en la institución educativa que se encuentra en la zona objeto de estudio.

\section{Palabras clave}

Vulnerabilidad, exclusión social, capacidades, libertades fundamentales, dignidad humana.

\begin{abstract}
This article analyzes the vulnerability with reference to educational of school-age population of the commune 5 on the north of Guadalajara de Buga city, according to the vulnerability approach which is mainly supported on the arguments proposed by Rubén Kaztman and Gustavo Busso as well as the capabilities focus developed by Martha Nussbaum. In the descriptive part, statistics on homicides and domestic violence is used with records on enrolment in preschool, primary and secondary education, and the education coverage in the city. In addition, the results of a poll

\footnotetext{
* Artículo tipo 2. De reflexión según la clasificación de Colciencias. Este trabajo es el resultado del proyecto de investigación "Situación de vulnerabilidad en lo educativo y cultural de la población escolar de la comuna 5 en la zona norte de Guadalajara de Buga" presentado en el marco de la convocatoria de la vicerrectoría de investigaciones de la Universidad del Valle 2014, en el cual participan como coautores los integrantes del grupo de investigación "Cátedra en Ética, Política y Derechos Humanos" de la Universidad del Valle sede Buga, Jaime Calero Sanz, Fernando Henao Franco y Jhonn Jairo Jaramillo Gómez

** Economista y Magister en Economía Aplicada Docente tiempo completo de la Universidad del Valle - Sede Buga Coordinador del Grupo de investigación de Cátedra en Ética, Política y Derechos humanos. E-Mail: jaime.aguilar@correounivalle.edu.co.
} 
delivered to a group of school teachers are incorporated as the main input of this study.

Keywords: Vulnerability, social exclusion, capabilities, fundamental freedoms, human dignity.

\section{Introducción}

En el desarrollo de la investigación: "justicia e inclusión social en poblaciones expuestas a vulnerabilidad en factores educativos y culturales: comuna 5 de Guadalajara de Buga", proyecto aprobado y financiado por la Vicerrectoría de Investigaciones de la Universidad del Valle para el período 2014 2015, se ha analizado la situación de vulnerabilidad de dicha población desde lo educativo, siguiendo tanto el enfoque de vulnerabilidad como el de las capacidades. Este artículo se escribe como resultado preliminar de dicha investigación, inicia analizando la concepción de pobreza, desigualdad y exclusión social; luego hace referencia al enfoque de la vulnerabilidad estudiado en la CEPAL, en especial por Rubén Kaztman y Gustavo Busso, para terminar el marco conceptual se aborda el enfoque de las capacidades de Martha C. Nussbaum. En la parte descriptiva se analizan estadísticas sobre violencia, en especial homicidios y violencia intrafamiliar ${ }^{1}$, haciendo énfasis en la violencia de pareja y contra los menores, ya que constituyen un ambiente desfavorable para el desarrollo educativo de niños y jóvenes. También se consideran las estadísticas sobre matrícula educativa y cobertura en Guadalajara de $\mathrm{Buga}^{2}$, que permiten determinar deficiencias de acceso al sistema educativo que enfrentan buena parte de la población escolar, convirtiéndose en factor de vulnerabilidad social y una gran injusticia social. Además, en cuanto a la información primaria, se han utilizado los resultados de la encuesta aplicada a una muestra de docentes de la institución educativa ubicada en la comuna 5 que atiende gran parte de la población escolar de ésta.

\footnotetext{
1 Para las estadísticas sobre violencia y maltrato intrafamiliar se han utilizados los informes del Instituto Nacional de Medicina Legal y Ciencias Forenses del año 2013 e información de la Secretaría de Salud Municipal de Guadalajara de Buga.

${ }^{2}$ Para las estadísticas de educación se han utilizado la información del Ministerio de Educación Nacional y de la Secretaria Municipal de Educación de Guadalajara de Buga.
} 


\section{Pobreza y desigualdad}

Las condiciones de marginación y exclusión social son un problema que históricamente ha afectado y en gran medida los países en vía de desarrollo, debido al modelo de producción y desarrollo adoptado, especialmente desde la década del noventa, caracterizado por una economía globalizada y con preponderancia del mercado en la asignación de recursos, la flexibilización laboral, favoreciendo el capital financiero y transnacional, en detrimento de los ingresos laborales de gran parte de la población y del gasto social. Como se puede apreciar en la tabla 1. América Latina y el Caribe muestran la mayor desigualdad a nivel mundial desde el punto de vista de los ingresos. ${ }^{* \star *}$ Colombia no es ajena a este fenómeno, evidenciando una gran inequidad y pobreza, asociado al problema de la violencia en sus diferentes modalidades, especialmente en la zona rural, con el consecuente fenómeno de desplazamiento forzado que lleva a condiciones de marginación social a millones de personas en el país. Es uno de los países más desiguales de América Latina y con un porcentaje del $10.4 \%$ de población en indigencia y pobreza extrema (ver tabla 2), lo que equivale a más de 4 millones de personas en dicha situación.

Tabla 1. Coeficiente de GINI América Latina y otras regiones del mundo, año 2009

\begin{tabular}{|c|l|}
\hline Región & GINI \\
\hline América Latina y el Caribe & 0,52 \\
África Subsahariana & 0,44 \\
Asía del Este y del Pacífico & 0,41 \\
África del Norte y medio & 0,38 \\
Oeste & 0,38 \\
Asia del sur & 0,35 \\
Europa del Oeste y Asia & 0,33 \\
Central & OCDE \\
\hline
\end{tabular}

Fuente: CEPAL, Panorama Económico y social de América Latina y El Caribe, 2013.

\footnotetext{
*** La desigualdad medida a través del coeficiente de Gini, oscila entre 0 y 1 , siendo 0 una perfecta igualdad y 1 total desigualdad.
} 
Tabla 2. Coeficiente de GINI América Latina y porcentaje de la población en indigencia y pobreza extrema, año 2012

\begin{tabular}{|l|r|c|}
\hline \multicolumn{1}{|c|}{ País } & \multicolumn{1}{l|}{$\begin{array}{l}\text { coeficiente } \\
\text { de GINI }\end{array}$} & $\begin{array}{l}\text { \% población en } \\
\text { indigencia } \\
\text { y pobreza extrema }\end{array}$ \\
\hline Brasil & 0,567 & 5,4 \\
Colombia & 0,536 & 10,4 \\
Chile & 0,516 & 3,1 \\
Costa Rica & 0,504 & 7,3 \\
México & 0,492 & 14,2 \\
Argentina & 0,475 & 1,7 \\
Bolivia & 0,472 & 18,7 \\
Ecuador & 0,468 & 12,9 \\
Perú & 0,449 & 5,5 \\
Venezuela & 0,405 & 9,7 \\
Uruguay & 0,379 & 1,1 \\
\hline Promedio América Latina & 0,496 & 11,3 \\
\hline
\end{tabular}

Fuente: CEPAL, Anuario Estadístico de América Latina y El Caribe, 2013.

\section{Exclusión social}

Superando la visión de la desigualdad fundamentada en el ingreso y la pobreza, el enfoque de la exclusión social enfatiza en el rompimiento del tejido social y el proceso de debilitamiento de los vínculos sociales del individuo con la comunidad (Subirats, Gomá y Brugué, 2005). Además analiza el proceso social que lleva a la dificultad que evidencian las personas para participar de forma vigorosa en la sociedad, centrándose en la falta de integración, participación social inadecuada e imposibilidad de realizar derechos sociales como educación, salud, vivienda, empleo, cultura, entre otros (García, Malo \& Rodríguez, 2000). Esta situación de exclusión social hace potencialmente vulnerables a quienes la padecen.

El enfoque de exclusión social, de acuerdo con Martínez (1999), no se limita a la carencia material, tiene en cuenta además de la desigualdad en la distribución de los recursos sociales, la segregación, estigmatización, rechazo social y carencia de relaciones que conllevan a una mayor exclusión social e imposibilitan el acceso a recursos, derechos o relaciones sociales vitales para una mayor integración social. En este sentido, la exclusión social conduce inevitablemente a incrementar el grado de vulnerabilidad de los individuos o poblaciones que padecen tal situación.

Para el análisis de las condiciones de vulnerabilidad desde lo educativo y cultural en la población en edad escolar en la zona norte de Guadalajara de Buga, 
se aborda tanto el enfoque de vulnerabilidad estudiado por Kaztman y Busso como el de capacidades desarrollado por Marta Nussbaum, los cuales se analizarán a continuación.

\section{Enfoque de la vulnerabilidad}

El enfoque de vulnerabilidad va más allá que el de exclusión social, porque hace relación a las circunstancias que potencian la posibilidad que tienen ciertos actores de sufrir un deterioro en su nivel de vida, tratando de determinar la tendencia de ciertas condiciones que aumentan el riesgo de enfrentar situaciones adversas que deteriorarían el bienestar social, lo que destaca el aspecto dinámico del enfoque. Uno de los primeros autores en abordar esta visión de la vulnerabilidad es Caroline Moser, concentrando su atención en los recursos, bienes 0 atributos, sean materiales $o$ intangibles, que pueden ser administrados para mejorar el bienestar o superar situaciones adversas. En este sentido la vulnerabilidad social se identifica con el conjunto de limitaciones o desventajas que las personas encuentran para acceder y usar los activos que se distribuyen en la sociedad (Moser, 1998). La vulnerabilidad social es resultado de los impactos provocados por el patrón de desarrollo vigente, pero también expresa la incapacidad de los grupos más débiles para enfrentarlos, neutralizarlos u obtener beneficios de dichos impactos. A menudo se relaciona la situación de pobreza de las personas con vulnerabilidad, sin embargo, la inseguridad e indefensión que caracterizan a ésta no son necesariamente atribuibles a la insuficiencia de ingresos propia de la pobreza. Esta forma de ver la vulnerabilidad ha sido tratada en Latinoamérica por la Comisión Económica para América Latina y el Caribe CEPAL, a través de autores como Rubén Kaztman y Gustavo Busso.

De acuerdo con Kaztman (1999), no es conveniente valorar los recursos que controlan los hogares sin relacionarlos con la estructura de oportunidades a las que pueden acceder, las cuales son cambiantes en el tiempo y para diferentes grupos sociales. Conforme a lo anterior, es necesario valorar tanto los recursos como la estructura de oportunidades a la que están expuestas las personas o colectivos, en razón a lo cual se puede aplicar a cualquier grupo de población, independiente de su nivel de pobreza o de su grado de exclusión social.

En el mismo sentido, Gustavo Busso argumenta que la vulnerabilidad es una noción multidimensional en la medida que afecta tanto a individuos, grupos y comunidades en distintos planos de su bienestar, de diversas formas y con diferentes intensidades, siendo considerada como el riesgo del individuo, hogar o comunidad de ser herido, lesionado o dañado ante cambios o permanencia de situaciones tanto externas como internas.

Conforme a lo anterior, el grado de vulnerabilidad depende de factores relacionados con los riesgos de origen natural y social, pero también de los 
recursos y estrategias con que cuentan individuos, hogares y comunidades para afrontar dichos riesgos. Esto a su vez hace necesario determinar la posibilidad de acceso a bienes básicos como la salud, la recreación, el trabajo, ingresos, y en particular, a la educación y la cultura, las dos dimensiones en las cuales la investigación se concentra.

Tiende a darse una correlación entre las diferentes variables de la vulnerabilidad, porque partiendo de una situación inicial, por ejemplo una debilidad en lo educativo, se pueden incrementar las condiciones de riesgo en lo laboral, en la salud, en lo económico, etc., lo que llevará a aumentar el nivel de vulnerabilidad del individuo, del hogar o del grupo social.

El enfoque de la vulnerabilidad, al hacer referencia al conjunto de activos que se poseen y de oportunidades que ofrece el entorno, permite determinar niveles de vulnerabilidad para diferentes personas, hogares o grupos sociales, siendo muy importante para la implementación de políticas públicas que permitan fortalecer la capacidad de respuesta de estos grupos ante los cambios del entorno y a mejorar este último para lograr una mayor integración social y disminuir sustancialmente los factores de riesgo que hacen vulnerables a las personas, contribuyendo a una mayor justicia social.

\section{Enfoque de las capacidades}

El enfoque de las capacidades, de acuerdo con Nussbaum (2012), además de preguntarse por el bienestar, se preocupa por las libertades disponibles para cada ser humano, argumentando también que las capacidades tienen una importancia central para las personas y se diferencian cualitativamente entre sí y no sólo cuantitativamente, siendo necesario comprender la naturaleza de cada capacidad.

Para comprender mejor el concepto es necesario analizar primero lo que se define como capacidades básicas de las personas, seguido de las capacidades internas, para luego examinar las capacidades combinadas y los funcionamientos, terminando con la relación entre capacidad y dignidad humana.

¿Qué son capacidades básicas? Los seres humanos traen consigo al mundo un equipamiento innato, es decir, unas facultades que posee por naturaleza y que no son resultado de lo que ha experimentado, hecho o percibido desde su nacimiento. A estas facultades innatas de la persona se les define como capacidades básicas, las cuales hacen posible el desarrollo y formación del ser humano (Nussbaum, 2012). Sostiene la autora que la nutrición materna y la experiencia prenatal desempeñan un papel importante en el despliegue y conformación de las capacidades básicas. En concordancia con lo anterior, se puede decir que el desarrollo cerebral del feto en el vientre está influenciado por el estado de salud y el bienestar emocional de la madre gestante. 
A partir del nacimiento se cuenta con capacidades internas, las cuales están condicionadas por el entorno, haciendo que se desarrollen las bases para aprendizajes posteriores, pues el crecimiento y desarrollo cerebral, resultantes de la sinergia entre un código genético y las experiencias de interacción con el ambiente, van a permitir un aprendizaje y el desarrollo de habilidades sociales, emocionales, cognitivas y motoras, que serán la base de toda una vida. En este sentido, se hace necesario definir las capacidades internas.

Las capacidades internas se relacionan con ciertas características de un individuo tales como personalidad, habilidades intelectuales y emocionales, estado de salud y de forma física, aprendizaje interiorizado, habilidades de percepción y movimiento, siendo estados de la persona fluidos y dinámicos. Éstos son rasgos y aptitudes entrenados y desarrollados, en muchos casos, en interacción con el entorno social, económico, familiar y político, por lo que son de gran importancia en el desarrollo de las capacidades combinadas (Nussbaum, 2012)

Las capacidades combinadas se definen como las oportunidades creadas por la combinación entre las facultades personales (internas) y el entorno político, social y económico, es decir, la totalidad de las oportunidades de que se disponen para elegir y para actuar en una situación política, social y económica concreta. Se definen también como la suma de las capacidades internas y las condiciones sociales, políticas y económicas en las que puede elegirse el funcionamiento de éstas, es decir, las capacidades internas hacen parte de las capacidades combinadas. En este sentido, estas últimas son un conjunto de oportunidades, habitualmente interrelacionadas, para elegir y actuar, determinando que es capaz de hacer y ser una persona. La capacidad significa oportunidad de seleccionar y la noción de libertad de elección está inscrita en el concepto de capacidad (Nussbaum, 2012).

El funcionamiento es la realización activa de una o más capacidades, son seres o haceres que a su vez vienen a ser los efectos o las ejecuciones de unas capacidades (Nussbaum, 2012). De allí la importancia de las capacidades, pues pueden convertirse en funcionamientos, pero de nada sirve que se garantice un funcionamiento como elegir libremente, sino se cuenta con la capacidad de hacerlo a conciencia. Por eso para la autora promover capacidades es promover áreas de libertad, lo que no es lo mismo que hacer que las personas funcionen en un determinado sentido, por lo que las capacidades tienen valor en sí mismas, entendidas como ámbitos de libertad y elección (Nussbaum, 2012).

El concepto de capacidad se relaciona con la noción de vida humana digna, ya que ciertas condiciones de vida facilitan a las personas una vida que es merecedora de la dignidad humana que ellas poseen, mientras otras condiciones no lo hacen. Además se argumenta que el enfoque de las capacidades se centra en la protección de ámbitos de libertad tan cruciales que su supresión hace que la vida no sea humanamente digna (Nussbaum, 2012). 
Para que la vida de una persona sea lo más digna posible, la autora plantea que se necesita como mínimo alcanzar diez capacidades centrales, las cuales se reproducen a continuación:

1. Vida: duración normal; 2. Salud física; 3. Integridad física; 4. Sentidos, imaginación y pensamiento; 5. Emociones; 6. Razón práctica; 7. Afiliación; 8. Otras especies; 9. Capacidad para jugar; y 10. Control sobre el entorno de cada uno. (Nussbaum, 2012: 53-55)

En el logro de dichas capacidades resulta indispensable un sistema educativo de calidad y acceso pleno al mismo, pues con una educación de baja calidad y población con acceso deficiente, resulta imposible que se puedan alcanzar, en especial capacidades como: sentido, imaginación y pensamiento; emociones; razón práctica; afiliación; y control sobre el entorno de cada uno.

A continuación se analizan dos de los factores que a través del desarrollo de la investigación se evidencia inciden de manera significativa en la vulnerabilidad en lo educativo de la población en edad escolar de Guadalajara de Buga, en particular en la Comuna 5 de la zona norte. Estos factores están relacionados con la violencia en el entorno familiar y social, así como el acceso y permanencia en el sistema educativo.

\section{Escenario violento como factor determinante de la vulnerabilidad en lo educativo}

El Instituto Nacional de Medicina legal y ciencias forenses de Colombia clasifica las muertes violentas en homicidios, suicidios, muertes accidentales de transporte, otras muertes accidentales y muertes violentas indeterminadas. Para el año 2013, según dicha institución, en la Ciudad de Guadalajara de Buga se evidenciaron 144 muertes violentas lo que equivale a una tasa de 124,6 por cada cien mil habitantes, siendo superior a la de Colombia y la del Valle como puede apreciarse en la tabla 3. De las anteriores, la mayor proporción corresponde a homicidios, aproximadamente el $72 \%$ (figura 1), con una tasa por cada cien mil habitantes de 84 , superiores también a la nacional y a la departamental. 
Tabla 3: Muertes violentas, según causa y tasa por cien mil habitantes en Colombia, Valle del Cauca y Guadalajara de Buga en el año 2013.

\begin{tabular}{|c|c|c|c|c|c|c|}
\hline \multirow{2}{*}{$\begin{array}{l}\text { Causa de } \\
\text { muerte } \\
\text { violentas }\end{array}$} & \multirow{2}{*}{\begin{tabular}{|l} 
Colombia \\
Casos
\end{tabular}} & \multirow{2}{*}{$\begin{array}{l}\text { Valle } \\
\text { del } \\
\text { Cauca } \\
\text { Tasa } x \\
100.000 \\
\text { hab. }\end{array}$} & \multirow{2}{*}{$\begin{array}{l}\begin{array}{l}\text { Guadalajara } \\
\text { de Buga }\end{array} \\
\text { Casos }\end{array}$} & \multirow[b]{2}{*}{$\begin{array}{l}\text { Tasa } x \\
100.000 \\
\text { hab. }\end{array}$} & \multirow[b]{2}{*}{ Casos } & \multirow[b]{2}{*}{$\begin{array}{l}\text { Tasa } x \\
100.000 \\
\text { hab. }\end{array}$} \\
\hline & & & & & & \\
\hline Homicidios & 14.294 & 30,33 & 3.426 & 75,8 & 97 & 83,9 \\
\hline $\begin{array}{l}\text { Accidente de } \\
\text { Transporte }\end{array}$ & 6.219 & 13,2 & 754 & 16,7 & 2 & 27,7 \\
\hline Accidental & 2.643 & 5,61 & 158 & 3,5 & 7 & 6,1 \\
\hline Suicidio & 1.810 & 3,84 & 158 & 3,5 & 6 & 5,2 \\
\hline Indeterminada & 1.657 & 3,52 & 213 & 4,7 & 2 & 1,7 \\
\hline Total & 26.623 & 56,5 & 4.709 & 104,2 & 44 & 124,6 \\
\hline
\end{tabular}

Fuente: Instituto Nacional de Medicina Legal y Ciencias Forenses.

Figura 1. Muertes violentas en Guadalajara de Buga - año 2013

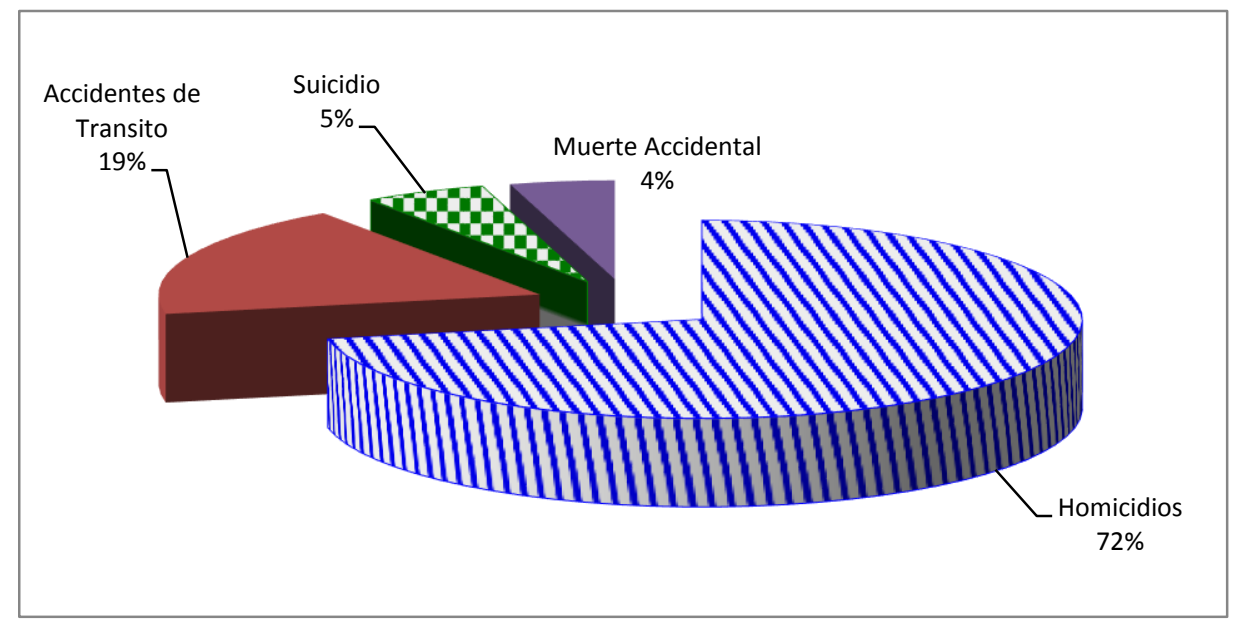

Fuente: Instituto Nacional de Medicina Legal y Ciencias Forenses.

Una tasa de homicidios superior a la nacional y departamental, da cuenta del ambiente de violencia en el que los niños y jóvenes de la ciudad deben convivir, especialmente los de la comuna 5 en la zona norte, donde se registra gran parte de los hechos violentos que ocurren en la ciudad, pues según un estudio de la Facultad de Salud de la Universidad del Valle (2012), alrededor del $42 \%$ de los homicidios en Guadalajara de Buga se concentraron en dicha comuna.

Si se analizan las lesiones no fatales, es decir, que no ocasionaron la muerte a la persona, se tiene que en la localidad se registraron 1.137 casos, con una tasa de 983,5 por cada cien mil habitantes, de los cuales la mayor parte corresponde a violencia intrapersonal y violencia intrafamiliar con tasas de $487 \mathrm{y}$ 
271 por cada cien mil habitantes, respectivamente, siendo superior a la de Colombia como a la del Valle (tabla 4). De la violencia intrafamiliar en Buga, la mayor proporción corresponde a la violencia de pareja y a la violencia contra niñas, niños y adolescentes, $66 \%$ y $12 \%$ en el mismo orden (figura 2 ).

Tabla 4: Lesiones no fatales y tasa por cien mil habitantes, según reconocimiento médico legal, en Colombia, Valle del Cauca y Guadalajara de Buga en el año 2013.

\begin{tabular}{|l|l|l|l|l|l|l|}
\hline \multirow{2}{*}{$\begin{array}{l}\text { Tipo de } \\
\text { reconocimiento } \\
\text { médico legal }\end{array}$} & Colombia & \multicolumn{2}{l|}{ Valle del Cauca } & \multicolumn{2}{l|}{$\begin{array}{l}\text { Guadalajara de } \\
\text { Buga }\end{array}$} \\
\cline { 2 - 7 } & Casos & $\begin{array}{l}\text { Tasa } x \\
100.000 \\
\text { hab. }\end{array}$ & Casos & $\begin{array}{l}\text { Tasa } x \\
100.000 \\
\text { hab. }\end{array}$ & Casos & $\begin{array}{l}\text { Tasa } x \\
100.000 \\
\text { hab. }\end{array}$ \\
\hline $\begin{array}{l}\text { Violencia } \\
\text { interpersonal }\end{array}$ & 158.798 & 337,0 & 11.567 & 255,9 & 563 & 487,0 \\
\hline $\begin{array}{l}\text { Violencia } \\
\text { intrafamiliar }\end{array}$ & 68.230 & 144,8 & 4.928 & 109,0 & 313 & 270,7 \\
\hline $\begin{array}{l}\text { Accidentes de } \\
\text { transporte }\end{array}$ & 41.823 & 88,8 & 4.089 & 90,5 & 193 & 166,9 \\
\hline Delito sexual & 20.739 & 44,0 & 1.791 & 39,6 & 61 & 52,8 \\
\hline $\begin{array}{l}\text { Lecciones } \\
\text { accidentales }\end{array}$ & 12.894 & 27,4 & 338 & 7,5 & 7 & 6,1 \\
\hline Total & 302.484 & 641,9 & 22.713 & 502,4 & 1.137 & 983,5 \\
\hline
\end{tabular}

Fuente: Instituto Nacional de Medicina Legal y Ciencias Forenses.

Figura 2. Violencia intrafamiliar en Guadalajara de Buga - año 2013

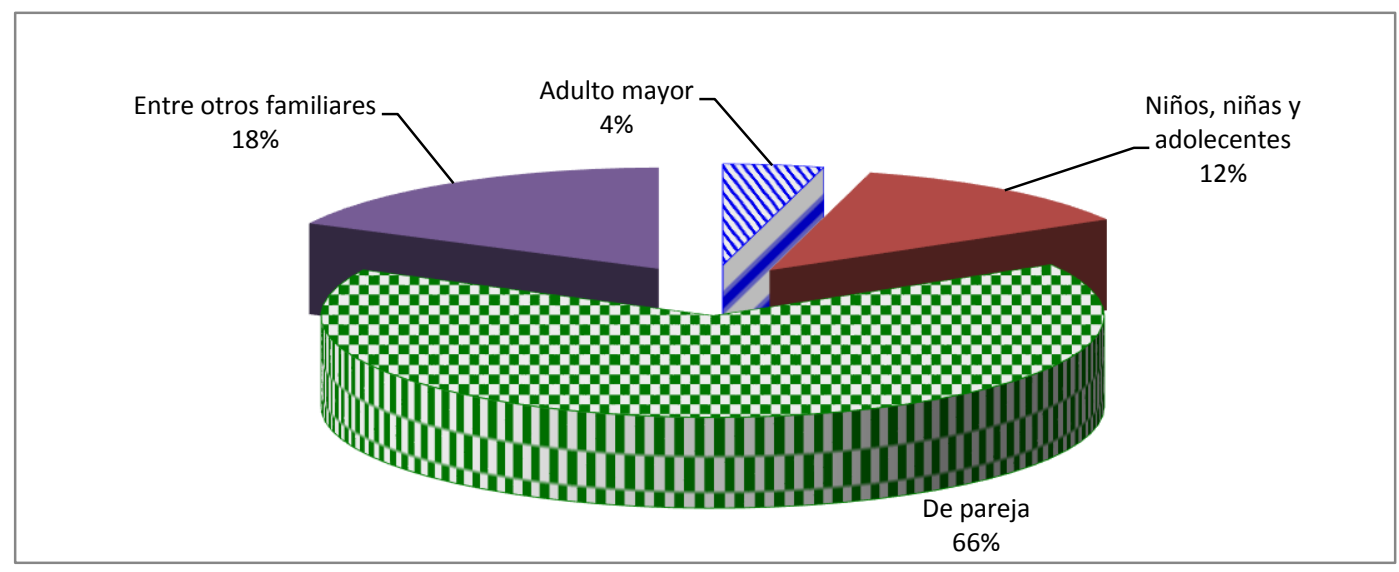

Fuente: Instituto Nacional de Medicina Legal y Ciencias Forenses. 
De acuerdo con la Secretaría de Salud municipal de Guadalajara de Buga, el $84 \%$ de la violencia intrafamiliar y sexual la padece el género femenino, mientras al género masculino le corresponde el $16 \%$. El principal escenario de este tipo de violencia es el hogar, pues le corresponde el $52 \%$ de los casos, seguido por la vía pública con el 25\%, a la escuela le corresponde el 6\% (figura 3 ).

Figura 3. Escenario de la violencia intrafamiliar y sexual en Guadalajara de Buga - año 2013

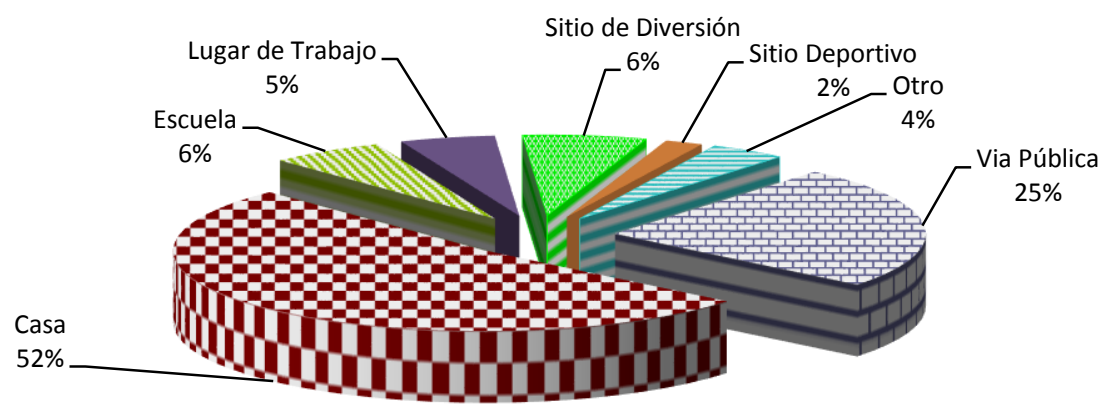

Fuente: SIVIGILA. Secretaria de Salud Municipal, Municipio de Guadalajara de Buga

En cuanto a la edad de la víctima, alrededor del $32 \%$ le corresponde a la población de 1 a 20 años (figura 4), que es la que se encuentra en edad escolar, incluyendo el nivel superior. Debe tenerse en cuenta que tiende a darse un subregistro, es decir, estas cifras pueden ser mayores. Manifiesta el Instituto Nacional de Medicina Legal y Ciencias Forenses, que se presenta inasistencia o deserción a citas programadas y la no denuncia por parte de algunas víctimas, aunque los hechos ocurren.

Figura 4. Grupo de Edad de la Victima en la violencia intrafamiliar y sexual en Guadalajara de Buga - año 2013

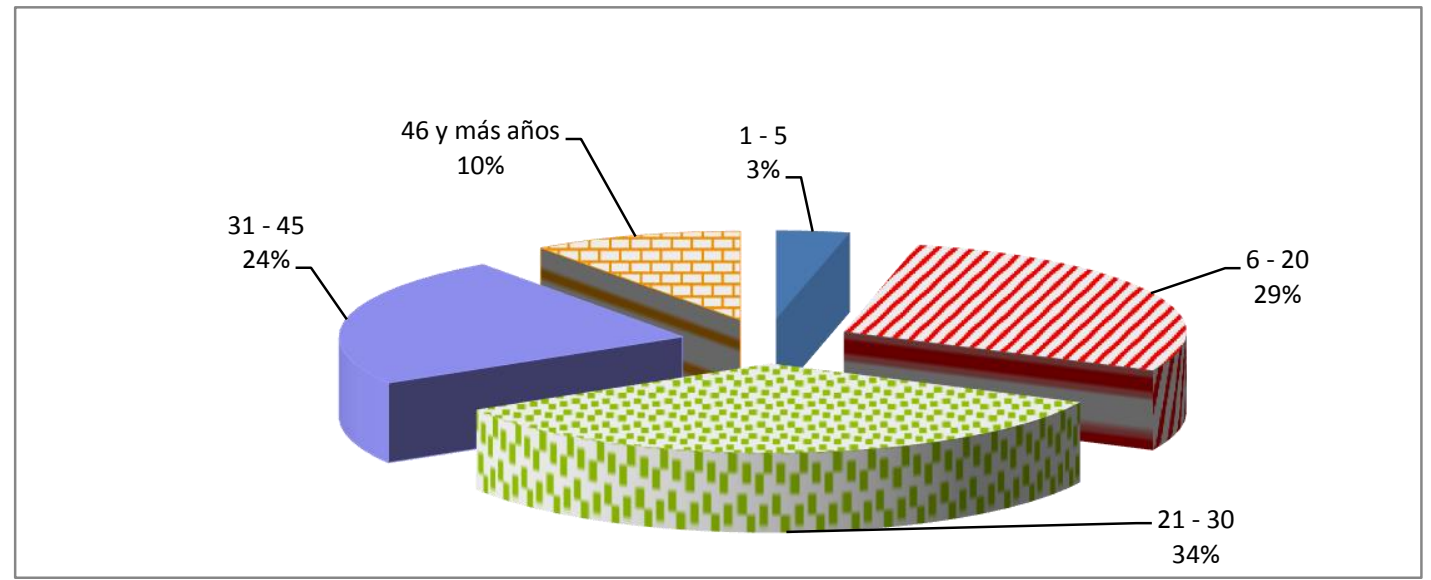

Fuente: SIVIGILA. Secretaria de Salud Municipal, Municipio de Guadalajara de Buga 
Según encuesta realizada a docentes de la institución educativa que ha servido como caso de estudio", se encontró que los profesores consideran en gran parte que las agresiones y conflictos en el colegio tienden a presentarse con frecuencia, pues alrededor del $70 \%$ los califican como relativamente, bastante y muy frecuente (figura 5), siendo principalmente agresiones verbales como insultar, amenazar e intimidar, ya que éstas se consideran también en un $70 \%$ entre relativa y bastante frecuente, y daños y robos con un $40 \%$ entre relativa y bastante frecuente y un $50 \%$ poco frecuente (figura 6 ).

Figura 5. Frecuencia de las agresiones y conflictos en Colegio zona Norte de Buga - año 2014

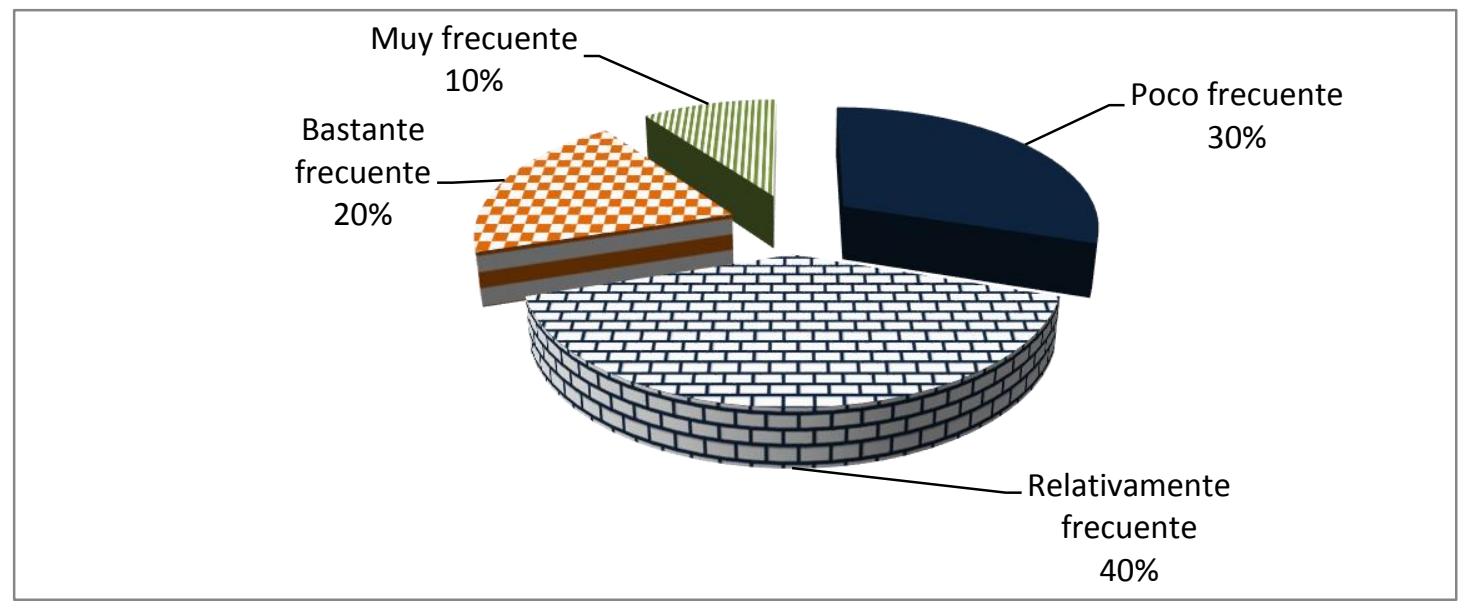

Fuente: Encuesta aplicada a docentes de Institución Educativa de la zona Norte de Buga.

\footnotetext{
* La encuesta se realizó a una muestra de 10 docentes de la Institución Educativa Agrícola de Guadalajara de Buga, la cual se localiza en la comuna 5 en la zona Norte de Guadalajara de Buga y atiende gran parte de la población escolar de este sector de la ciudad.
} 
Figura 6. Frecuencia de las agresiones verbales y daños y robos en Colegio zona Norte de Buga - año 2014

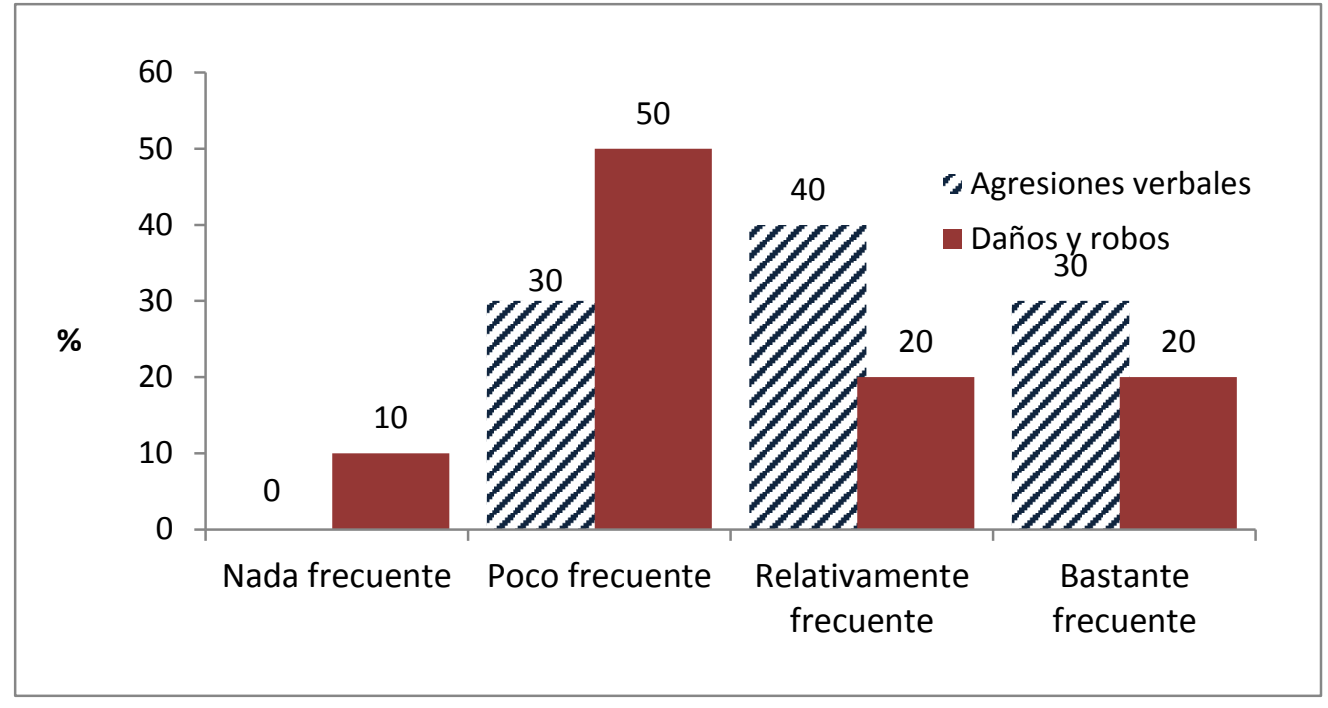

Fuente: Encuesta aplicada a docentes de Institución Educativa de la zona Norte de Buga.

Alrededor del $40 \%$ de los profesores encuestados consideró que las agresiones de los alumnos hacia los docentes son entre relativamente y bastante frecuente, un $50 \%$ manifiesta que se presentan aunque con poca frecuencia (figura 7); siendo las agresiones más frecuentes las verbales y los cometarios y rumores sobre el profesor (figura 8), lo que permite deducir que los docentes consideran las agresiones con algún grado de frecuencia.

Figura 7. Frecuencia de agresiones de alumnos a docentes en Colegio Zona Norte de Buga - año 2014

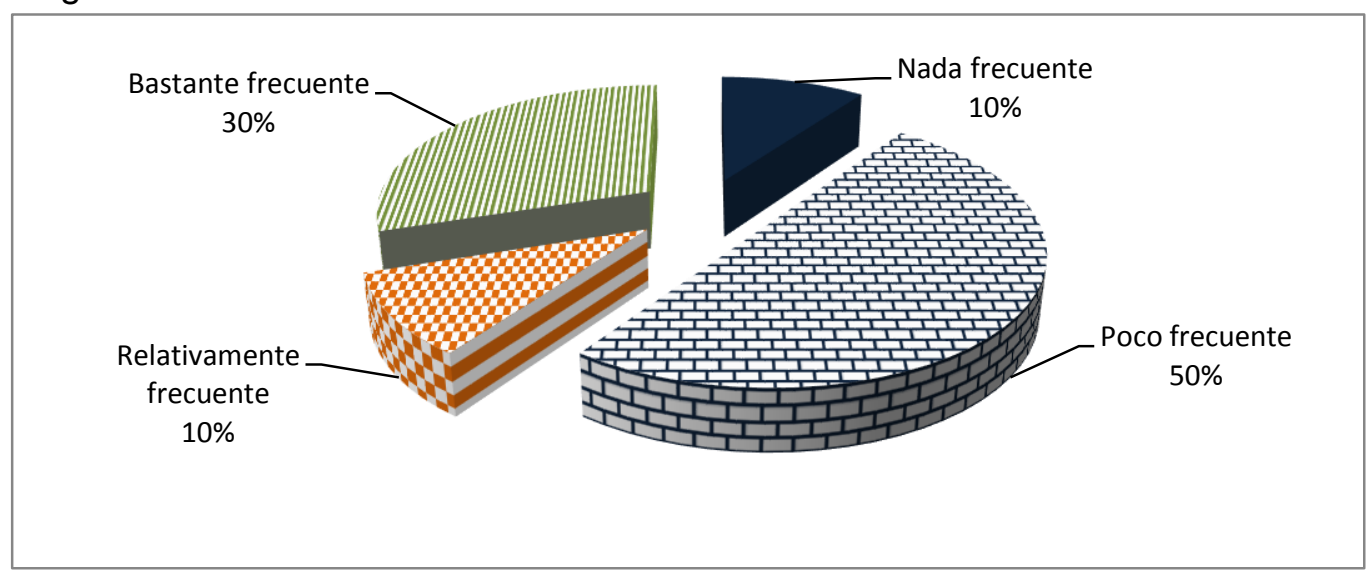

Fuente: Encuesta aplicada a docentes de Institución Educativa de la zona Norte de Buga. 
Figura 8. Agresiones más frecuentes de alumnos hacia los docentes en Colegio Zona Norte de Buga - año 2014

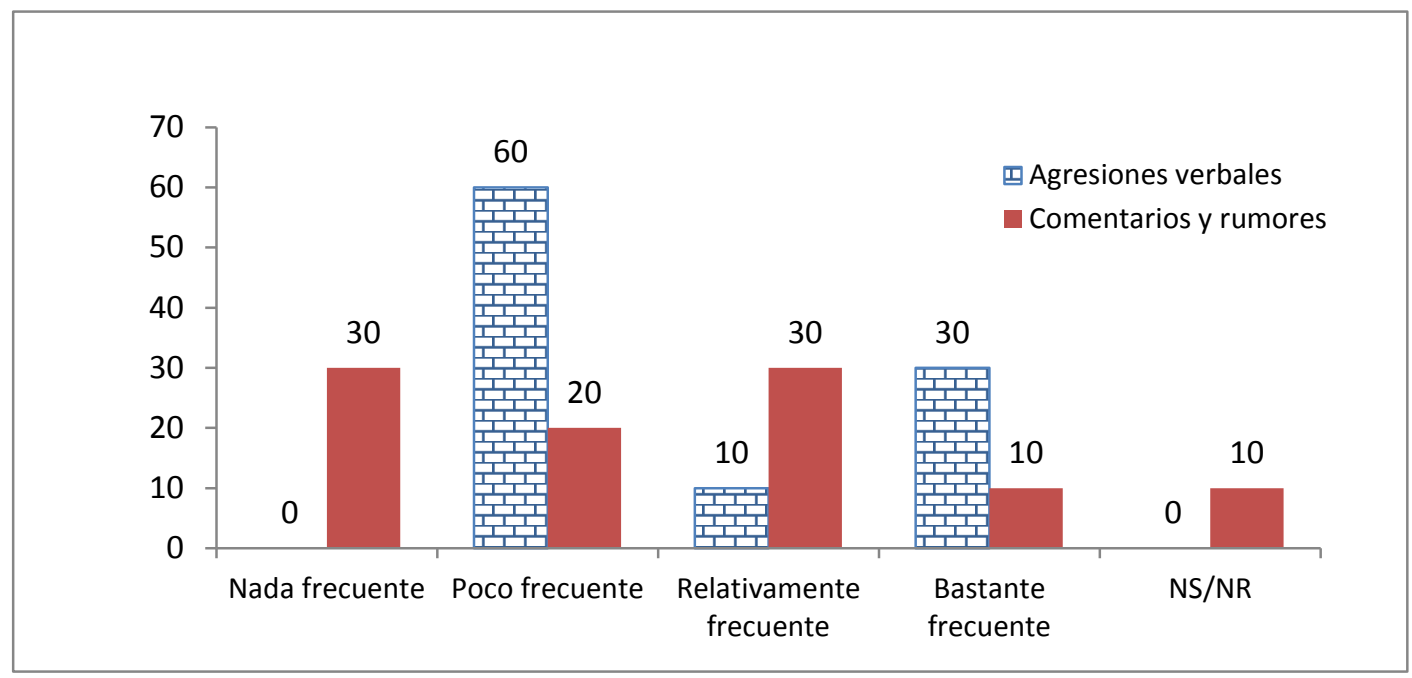

Fuente: Encuesta aplicada a docentes de Institución Educativa de la zona Norte de Buga.

Se puede advertir que la violencia intrafamiliar y un entorno violento al hogar son condiciones que inciden para que se presente un clima de agresiones en el colegio, pues los estudiantes tienden a replicar en el centro educativo, las situaciones que acontecen en su vivienda.

También se preguntó a los docentes, si en el colegio se presentaban niños con evidencia de maltrato en el hogar, los cuales manifestaron que se evidencia en los alumnos la posibilidad que estén padeciendo en alguna medida dicha situación (figura 9). Esto de alguna manera está relacionado con las estadísticas del Instituto Nacional de Medicina Legal y Ciencias Forenses, presentadas en párrafos anteriores, las cuales indican la evidencia de maltrato intrafamiliar. Lo anterior permite intuir las difíciles condiciones que deben enfrentar los niños y jóvenes, constituyéndose además en limitante para el desarrollo de capacidades del individuo.

Figura 9. Evidencia de maltrato en el hogar según docentes Colegio Zona Norte de Buga - año 2014 


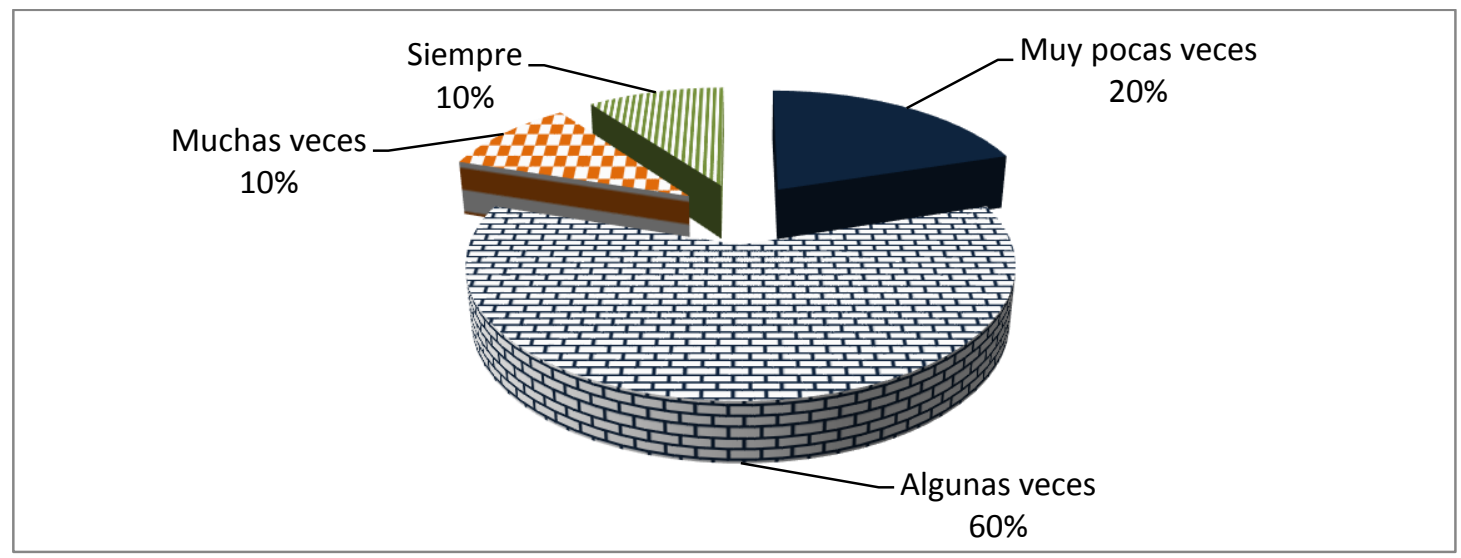

Fuente: Encuesta aplicada a docentes de Institución Educativa de la zona Norte de Buga.

El $40 \%$ de los docentes manifiesta que en el diálogo con los acudientes, estos últimos escuchan pero no se llega a acuerdos, mientras otro $40 \%$ manifiesta no saber del tema (figura 10), lo que indudablemente indica que es muy débil la comunicación con los familiares o responsables de los estudiantes. Además, el $50 \%$ de los profesores manifiesta que el nivel de interés y seguimiento mostrado por los acudientes tiende a estar entre poco y moderado (figura 11). Esto se ve reflejado en que aproximadamente el $90 \%$ de los docentes considera que es entre prioritario y muy prioritario la participación de las familias en la solución de los problemas de convivencia en el colegio (figura 12).

Figura 10. Percepción del docente en el diálogo con los acudientes de estudiantes en Colegio Zona Norte de Buga - año 2014

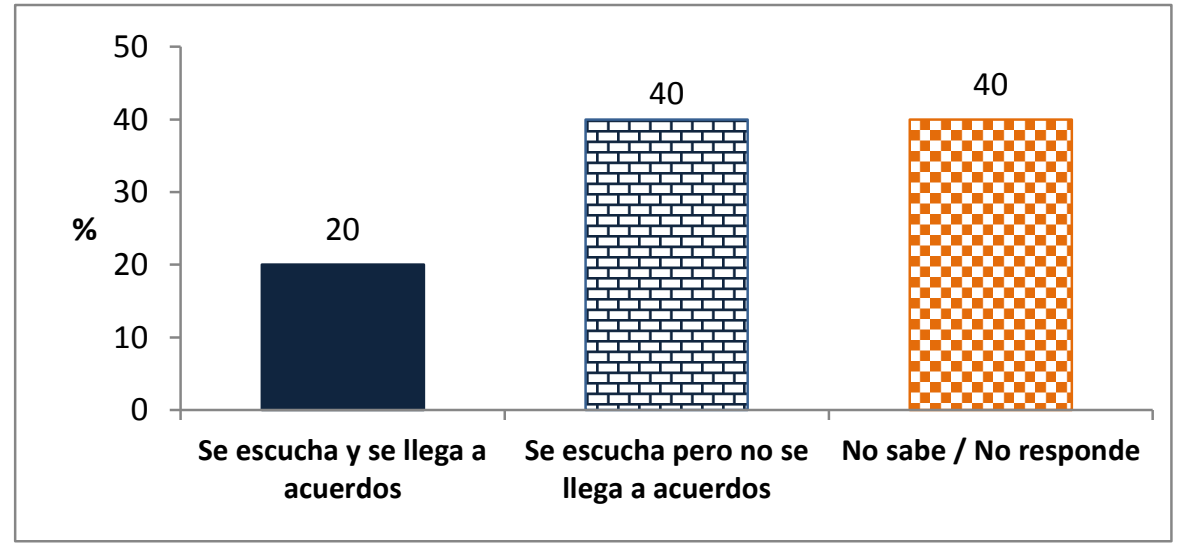

Fuente: Encuesta aplicada a docentes de Institución Educativa de la zona Norte de Buga. 
Figura 11. Nivel de interés y seguimiento en los diálogos con los acudientes de estudiantes en Colegio zona Norte de Buga - año 2014

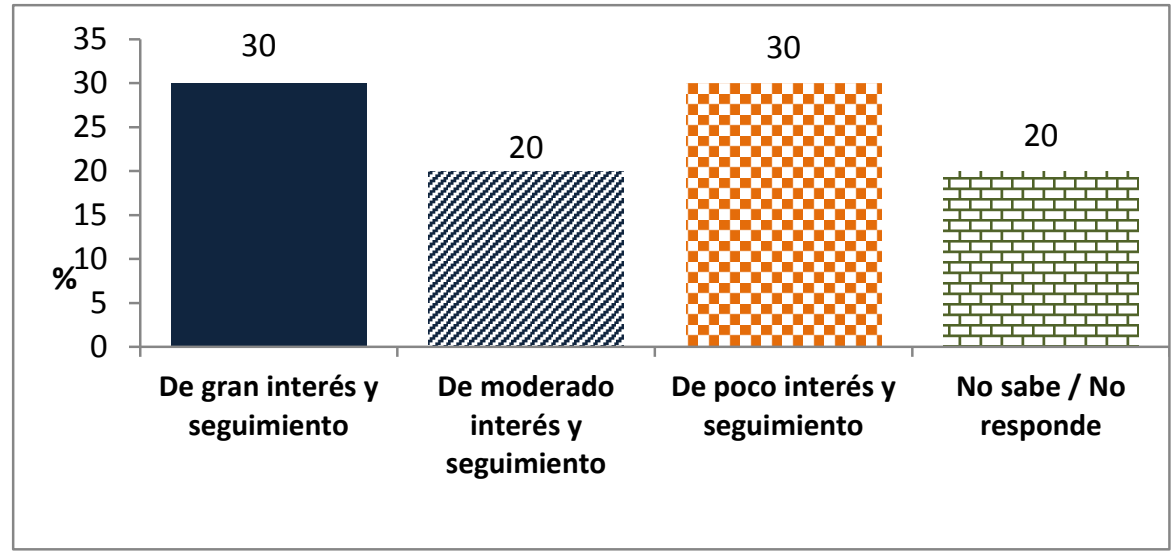

Fuente: Encuesta aplicada a docentes de Institución Educativa de la zona Norte de Buga.

Figura 12. Cómo consideran los docentes la participación de las familias en la solución del problema de convivencia en el colegio Zona Norte de Buga - año 2014

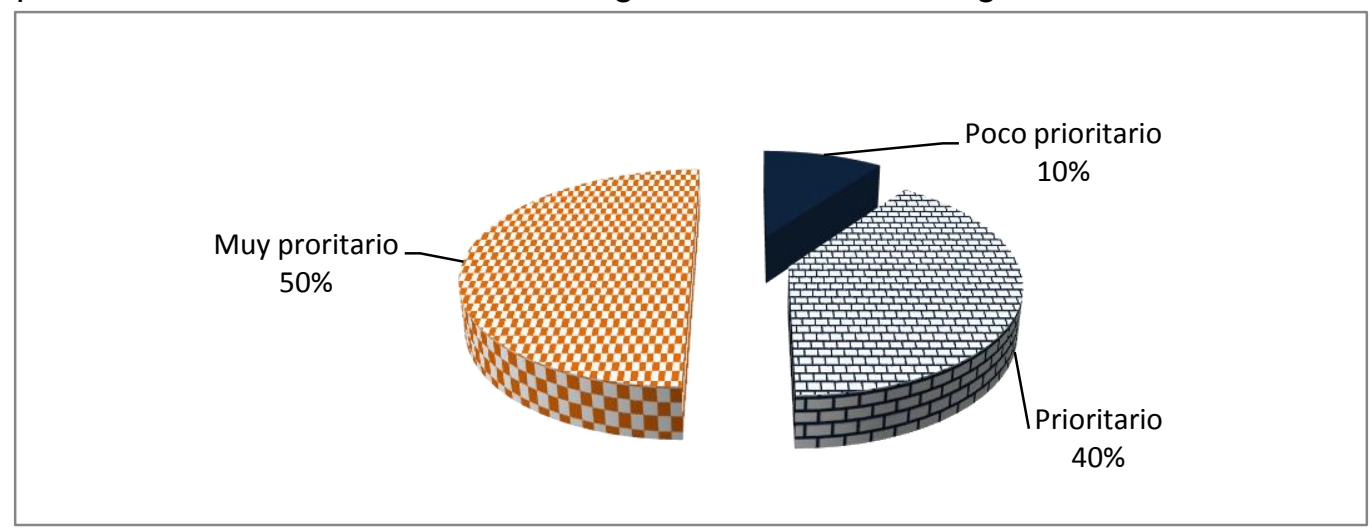

Fuente: Encuesta aplicada a docentes de Institución Educativa de la zona Norte de Buga.

Del análisis descriptivo anterior se puede deducir que el hogar, núcleo básico donde el niño y el joven puede desarrollar su potencialidad, es un escenario perturbado por situaciones de violencia intrafamiliar, principalmente las agresiones entre parejas, pero también padeciéndola físicamente el mismo escolar. Además, como ya se mencionó, el ambiente exterior del hogar está marcado por un escenario de violencia, especialmente homicidios, recuérdese, una tasa superior a la nacional y departamental. Esto va a dificultar las posibilidades para que se puedan aprovechar el conjunto de oportunidades que pueda tener a su disposición, porque de acuerdo con Busso y siguiendo el enfoque de la vulnerabilidad, tienden a crearse inseguridades permanentes que van a incapacitar al niño y al adolescente para actuar en el futuro. 
Otro aspecto a tener en cuenta en el escenario marcado por la violencia intrafamiliar, especialmente la de pareja, como ocurre en Guadalajara de Buga, es la experiencia prenatal que, siguiendo a Nussbaum, va a determinar la conformación de capacidades básicas del individuo al nacer, ya que el estado físico y emocional de la madre gestante es determinante en este sentido. Pero además, el entorno del hogar, marcado por la violencia y un ambiente de agresiones frecuentes en el centro educativo, dificultan el logro de capacidades internas como la personalidad, las habilidades intelectuales y emocionales, que de acuerdo con el enfoque de las capacidades expuesto por la misma autora, el ambiente familiar y el escolar son entornos esenciales para el desarrollo de estas características.

Resulta importante establecer la relación con la quinta de las diez capacidades centrales establecidas por Nussbaum, la cual hace referencia a las emociones, relacionadas con los vínculos afectivos del individuo con las personas, con el desarrollo emocional sin miedos y ansiedades, lo cual permite la asociación humana, a su vez esencial para el desarrollo del sujeto. En este sentido, el escenario de los niños y jóvenes de la ciudad, especialmente de la zona norte, caracterizado por la violencia intrafamiliar, el alto índice de homicidios y las situaciones de agresiones con alguna frecuencia en el medio escolar, no es el más propicio para el logro de esta capacidad central.

La UNESCO ha identificado la violencia y los malos tratos imperantes en la sociedad, como uno de los factores sociales que ha tenido incidencia significativa en un gran número de alumnos en diferentes países, constituyéndose en una de las situaciones de exclusión (Unesco, 2003). Por consiguiente, esta variable se convierte en un factor de vulnerabilidad para la zona norte de la ciudad de Buga como se ha podido establecer en el desarrollo de la investigación.

\section{La educación en Guadalajara de Buga como factor de vulnerabilidad}

La matrícula en educación en Guadalajara de Buga no ha crecido significativamente entre los años 2005 y 2013, especialmente en los niveles de primaria, secundaria y media como se puede apreciar en la figura 13. Lo anterior se refleja en los niveles de cobertura, que no tienen un crecimiento significativo y sigue estando en niveles preocupantes. La cobertura bruta para el nivel de preescolar, en el período 2005 - 2013, ha oscilado en términos porcentuales entre 104 y 115, siendo de 106 por ciento para el último año. En el nivel de primaria es superior a 120 en el mismo período, alcanzando en el año 2013 un porcentaje de 134. En el nivel de secundaria pasó de 107 a 135 por ciento y en el nivel de educación media de 76 a 111 por ciento en igual período como puede corroborarse en la tabla 5. Por supuesto, el porcentaje es superior a 100, pues 
incluye población en extra edad, es decir, estudiantes con edad superior a la que corresponde al nivel escolar en el que se encuentran, lo que indica el rezago que presentan en el ciclo educativo algunos estudiantes.

Figura 13. Matrícula por nivel en Guadalajara de Buga - período 2002 - 2014

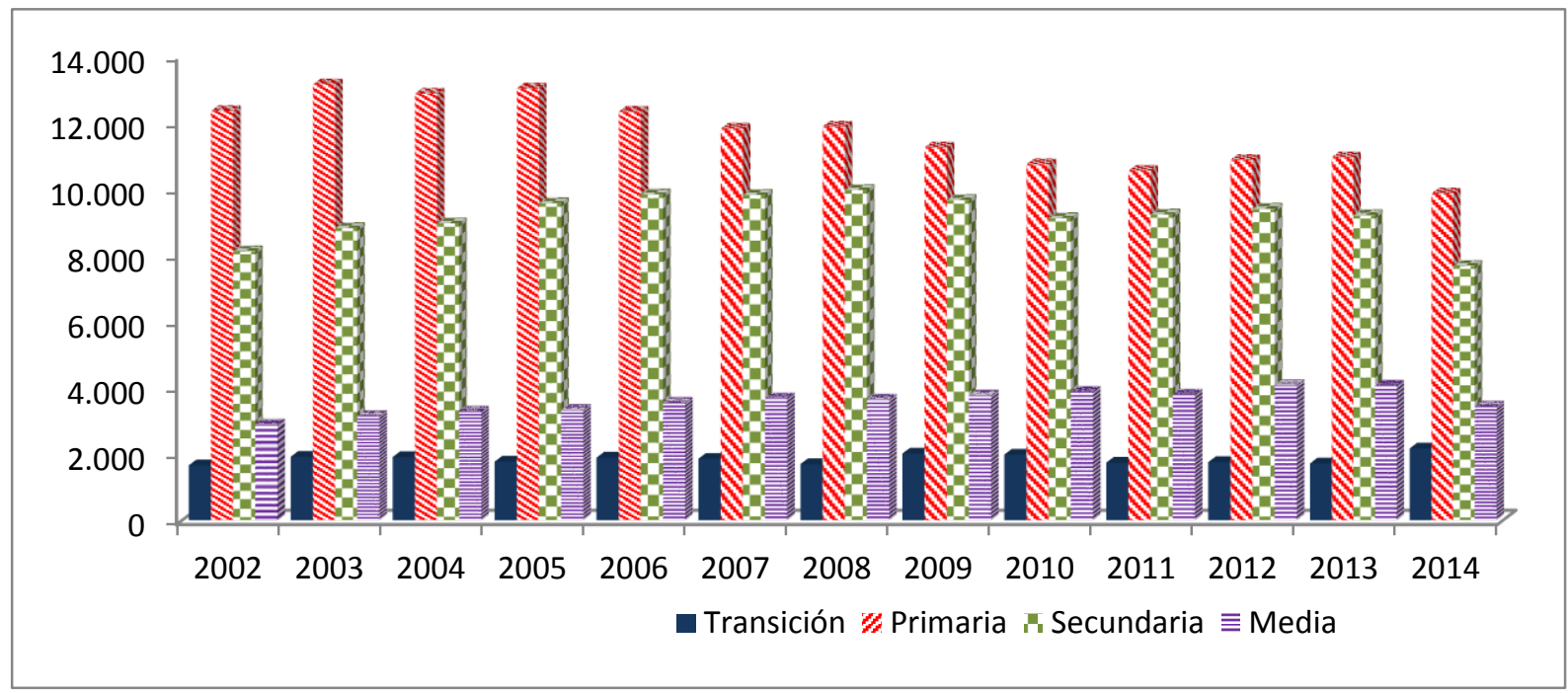

Fuente: MEN - SIMAT. Secretaría de Educación Municipal de Guadalajara Buga.

Tabla 5. Guadalajara de Buga: cobertura bruta por nivel - período 2005 - 2013 (\%)

\begin{tabular}{|l|l|l|l|l|l|l|l|l|l|}
\hline $\begin{array}{l}\text { Nivel } \\
\text { educativo }\end{array}$ & 005 & 006 & 007 & 008 & 009 & 010 & 011 & 012 & 013 \\
\hline Preescolar & 07 & 08 & 09 & 11 & 05 & 04 & 15 & 08 & 06 \\
\hline Primaria & 28 & 5 & 24 & 29 & 27 & 25 & 26 & 33 & 34 \\
\hline Secundaria & 07 & 13 & 16 & 2 & 22 & 20 & 26 & 33 & 35 \\
\hline Media & 6 & 1 & 5 & 5 & 0 & 5 & 7 & 08 & 11 \\
\hline
\end{tabular}

Fuente: MEN - SIMAT.

Al observar la cobertura neta, que tiene en cuenta sólo la población matriculada en un ciclo educativo que tiene la edad correspondiente para dicho nivel escolar, se observa que para preescolar la tasa ha disminuido a partir del año 2011 y en el 2013 es apenas del 33 por ciento, siendo esto preocupante, pues indica que alrededor del 67 por ciento de los niños que deberían estar en este ciclo educativo no lo están (tabla 6). En el caso del nivel primaria, se puede decir que tiende a presentarse una plena cobertura durante el período 2005 - 2013, ya que la tasa ha oscilado alrededor del 100 por ciento; pero para los ciclos siguientes la tasa tiende a bajar, siendo la de secundaria inferior al 90 por ciento y la de media al 60 por ciento, indicando esto que una parte importante de los estudiantes van quedando rezagados en ciclos no correspondientes a su edad o van siendo expulsados del sistema educativo. 
Tabla 6. Guadalajara de Buga: cobertura neta por nivel - período 2005 - 2013

\begin{tabular}{|l|l|l|l|l|l|l|l|l|l|}
\hline $\begin{array}{l}\text { Nivel } \\
\text { educativo }\end{array}$ & 005 & 006 & 007 & 008 & 009 & 010 & 011 & 012 & 013 \\
\hline Preescolar & 3 & 3 & 0 & 6 & 9 & 6 & 7 & 7 & 3 \\
\hline Primaria & 01 & 02 & 00 & 00 & 9 & 9 & 03 & 03 & 9 \\
\hline Secundaria & 6 & 0 & 2 & 7 & 7 & 6 & 0 & 9 & 9 \\
\hline Media & 3 & 7 & 8 & 8 & 1 & 3 & 4 & 6 & 9 \\
\hline
\end{tabular}

Fuente: MEN - SIMAT.

Es preocupante el bajo nivel de cobertura neta en la educación preescolar, tan fundamental para potenciar el desarrollo socio afectivo y cognitivo del niño en las primeras etapas de su vida. Lo anterior implica un mayor grado de marginación social y vulnerabilidad en la población que no puede acceder a este ciclo educativo. La UNESCO ha definido los siguientes objetivos para la educación inicial o preescolar: promoción del desarrollo integral de los niños y niñas; construcción de los niños y niñas como sujetos de derechos; formación y promoción de la participación de las familias en los procesos de desarrollo infantil; favorecer la continuidad con el ciclo de educación básica primaria; e integración social y equidad (UNESCO, 2010). Lo anterior permite deducir la situación de vulnerabilidad a la que están expuestos los niños en edad preescolar en Guadalajara de Buga, particularmente los de la comuna 5 de la zona norte de la ciudad.

La población escolar en la comuna 5 de Buga, en los niveles de preescolar, primaria, básica secundaria y media, es atendida por la Institución Educativa Agrícola de Guadalajara de Buga, que contribuye con aproximadamente el 13\% del total de la matrícula del sector oficial de la ciudad. Es importante resaltar que para el 2013, esta institución participó con el 36\% del total de los reprobados de las instituciones educativas oficiales, lo que equivale a 365 estudiantes que no aprobaron su respectivo curso (tabla 7), indicando esto el alto nivel de reprobación y rezago en el ciclo educativo, así como la posible deserción. 
Tabla 7. Reprobados y graduados en Instituciones educativas oficiales en Guadalajara de Buga, año 2013

\begin{tabular}{|c|c|c|c|c|}
\hline INSTITUCIONES & REPROBADOS & $\%$ & GRADUADOS & $\%$ \\
\hline NARCISO CABAL SALCEDO & 60 & 0 & 88 & 0 \\
\hline \multicolumn{5}{|l|}{ AGRICOLA DE GUADALAJARA } \\
\hline DE BUGA & 365 & 6,2 & 140 & 1,1 \\
\hline \multicolumn{5}{|l|}{ MANUEL ANTONIO } \\
\hline SANCLEMENTE & 71 & 0 & 79 & ,3 \\
\hline JOSE MARIA VILLEGAS & 5 & ,5 & 119 &, 5 \\
\hline SAN VICENTE & 53 & ,3 & 183 & 4,6 \\
\hline TULIO ENRIQUE TASCON & 105 & 0,4 & 166 & 3,2 \\
\hline ACADEMICO & 169 & 6,8 & 165 & 3,1 \\
\hline GRAN COLOMBIA & 170 & 6,9 & 86 & ,8 \\
\hline EL PLACER & 0 &, 0 & 29 & 3 \\
\hline ANGEL CUADROS & 10 & 0 & 82 &, 5 \\
\hline LA MAGDALENA & 0 & 0 & 7 & 6 \\
\hline \multicolumn{5}{|l|}{ TULIO ENRIQUE TASCON } \\
\hline \multicolumn{5}{|l|}{ AGROPECUARIO } \\
\hline \multicolumn{4}{|l|}{ NUESTRA SEÑORA DE } & ,6 \\
\hline \multirow[t]{2}{*}{ FATIMA } & 0 & 0 & 63 & 0 \\
\hline & \multicolumn{4}{|c|}{1} \\
\hline TOTAL & 1008 & 0,0 & 1256 & 00,0 \\
\hline
\end{tabular}

Fuente: Secretaría de Educación Municipal de Guadalajara de Buga, Plataforma SIMAT.

El alto nivel de reprobación en la institución educativa que atiende la mayor parte de la zona norte de Buga, puede ser resultado de las difíciles condiciones en el hogar y el entorno que los niños y jóvenes deben enfrentar en su desarrollo humano. Como señala el Comité sobre los Derechos del Niño de las Naciones Unidas: "Los niños son en mayor grado vulnerables al deterioro ocasionado por relaciones poco fiables o inestables con padres y cuidadores, o por el hecho de crecer en condiciones de pobreza y privación extremas, rodeados de conflictos y violencia, desplazados de sus hogares como refugiados, o por cualquier otro cúmulo de adversidades perjudiciales para su bienestar" (UNESCO, 2010).

Por otra parte, la baja cobertura en el nivel educativo preescolar, así como en los niveles de secundaria y media, significa que gran parte de los niños en edad para estos ciclos educativos están por fuera del sistema, lo cual implica que el desarrollo de sus potencialidades será limitado, por lo que se encontrarán en gran desventaja en un futuro para aprovechar las oportunidades que enfrentarán en su vida. Como manifiesta Nussbaum, será muy difícil que puedan desarrollar 
sus capacidades, es decir, desarrollar sus facultades internas y poder elegir y actuar en una situación social, económica y política determinada. La educación es fundamental en la cuarta de las diez capacidades, planteadas por la autora, referida a los sentidos, la imaginación y el pensamiento, siendo fundamental en la disminución de la exclusión y la marginación social y a una mayor equidad social, por lo son preocupantes los problemas de cobertura, atraso y reprobación señalados en párrafos anteriores.

\section{Conclusiones}

El enfoque de la vulnerabilidad va más allá de la pobreza y la limitación material, tomando en cuenta además, el acceso a las oportunidades, el desamparo ante cambios en el entorno, la inseguridad para actuar y lograr mejores niveles de vida. Trata de determinar niveles de vulnerabilidad para diferentes grupos tomando en cuenta la estructura de activos que poseen y las oportunidades que se encuentran en el entorno.

El enfoque de las capacidades propuesto por Nussbaum, se centra en las realizaciones que pueden lograr las personas y grupos sociales por medio del desarrollo de un conjunto de capacidades a partir de facultades innatas de la persona, logrando el despliegue de características como habilidades intelectuales, físicas y emocionales en interacción con el entorno familiar, social, económico y político. El desarrollo de las capacidades, de acuerdo con la autora, garantiza la existencia de espacios de libertad humana y por ende una vida humana digna.

Los niños y jóvenes escolares que viven en la comuna 5 de Guadalajara de Buga, se encuentran expuestos a situaciones de maltrato intrafamiliar y a un entorno del hogar, barrio o comuna, influenciado por la violencia, especialmente un alto grado de homicidios, así como un contexto escolar con agresiones frecuentes. Este ambiente se configura en un gran impedimento para un adecuado desempeño escolar, y por ende, al desarrollo de capacidades y al logro de una vida humana digna como lo argumenta Martha Nussbaum. Por consiguiente, se puede deducir que la población escolar de la zona objeto de estudio tiende a ser vulnerable, especialmente por las condiciones de violencia, tanto intrafamiliar como por la evidenciada en el entorno del hogar, pero también por agresiones frecuentes que se evidencian en el ambiente escolar.

En Guadalajara de Buga, especialmente en la zona norte, gran parte de la población en edad de preescolar se encuentra por fuera del sistema educativo, lo que se constituye en un factor de vulnerabilidad, pues la educación en este nivel, a través del desarrollo socio afectivo y cognitivo del individuo, permite el desarrollo de las capacidades internas, así como de las combinadas, facilitando en el futuro la realización de las mismas, es decir, traducir dichas capacidades en funcionamientos. 
La cobertura neta en los niveles escolares de secundaria y media disminuye con relación a la primaria, indicando el nivel de reprobación y posible deserción de los jóvenes del sistema educativo, lo que se corrobora con el alto nivel de reprobación registrado en la institución educativa que atiende en gran medida la población escolar de la zona norte. Esto implica una condición de gran vulnerabilidad desde lo educativo y cultural, puesto que la educación y el sistema educativo juega un papel de gran importancia en el desarrollo de capacidades internas y, como lo manifestó Adam Smith (citado por Nussbaum, 2012), "la privación de la educación hace que una persona esté mutilada y deformada en una parte del carácter de la naturaleza humana incluso más esencial".

El proyecto de investigación se había propuesto identificar las principales variables que determinan la vulnerabilidad en lo educativo, para establecer factores de riesgo. En lo desarrollado de la investigación hasta el momento, se ha logrado determinar los siguientes factores de riesgo y las respectivas variables:

\begin{tabular}{|c|c|c|}
\hline Factor & Variable & Descripción \\
\hline $\begin{array}{l}\text { 1. Precarie } \\
\text { dad institucional }\end{array}$ & $\begin{array}{l}1.1 \text { Cobertura } \\
\text { escolar }\end{array}$ & $\begin{array}{l}\text { 1.1.1 Determinada por la } \\
\text { baja cobertura en educación, } \\
\text { especialmente en educación } \\
\text { preescolar y en los ciclos de } \\
\text { secundaria y media, en los cuales } \\
\text { la cobertura baja con relación a la } \\
\text { primaria. }\end{array}$ \\
\hline $\begin{array}{l}\text { 2. Precarie } \\
\text { dad escolar }\end{array}$ & $\begin{array}{l}2.1 \\
\text { Reprobación } \\
\\
2.2 \text { Clima } \\
\text { escolar }\end{array}$ & $\begin{array}{l}\quad \text { 2.1.1 Manifestada en la } \\
\text { significativa tasa de reprobación de } \\
\text { estudiantes, lo que lleva a retraso } \\
\text { en el ciclo escolar y a la posible } \\
\text { deserción. } \\
\quad \text { 2.2.1 Revelado en el } \\
\text { ambiente escolar, caracterizado } \\
\text { por las agresiones que se } \\
\text { evidencian con frecuencia. }\end{array}$ \\
\hline $\begin{array}{l}\text { 3. Precarie } \\
\text { dad familiar }\end{array}$ & $\begin{array}{l}\text { 3.1 Violencia } \\
\text { intrafamiliar } \\
\text { 3.2 Entorno } \\
\text { violento al hogar }\end{array}$ & $\begin{array}{l}\text { 3.1.1 Revelada, } \\
\text { especialmente, en la violencia de } \\
\text { pareja y contra los menores. } \\
\text { 3.2.1 Evidenciado en un alto } \\
\text { índice de homicidios que } \\
\text { caracterizan el entorno del hogar. }\end{array}$ \\
\hline
\end{tabular}


Como el enfoque de las capacidades hace énfasis en la dignidad, determina mayor importancia a las políticas públicas, por lo que se hace necesario la elección de políticas que protegen y apoyan la agencia (la capacidad de acción de individuos), en especial una política que promueva las capacidades en materia de educación. En este sentido, se requiere una política educativa para Guadalajara de Buga, liderada por la administración municipal, especialmente por la Secretaría de Educación, que prepare a los niños y jóvenes para que sean capaces de informarse sobre los asuntos fundamentales que deberán enfrentar como ciudadanos de una democracia, ya sea como agentes sociales, políticos, económicos, etc. No puede ser sólida una democracia si no tiene el apoyo de ciudadanos preparados para que ésta se conserve lo más vigorosa posible (Nussbaum, 2010).

Lo anterior, implica mejorar los procesos de evaluación de los estudiantes, modificar la estructura curricular, haciéndola más flexible e innovadora, mejorando los procesos de enseñanza y aprendizaje, además de estrategias orientadas a aumentar la formación de los docentes, un mayor apoyo y reconocimiento social a éstos, pero también una evaluación adecuada del desempeño en su labor como educadores. Esto permitirá que los profesores tengan la capacidad de aportar más en el proceso educativo de los estudiantes. En este sentido se plantean las siguientes acciones:

- Desarrollar programas que permitan valorar e identificar las necesidades educativas específicas de los alumnos, de acuerdo a las características diferenciadoras de los diferentes grupos.

- Estructurar un modelo curricular para el sistema educativo municipal que sea diversificado, orientado a la formación en desarrollo de facultades, respetando particularidades (reconocimiento del sujeto), con pertinencia social y personal, aprendiendo en el momento oportuno y en felicidad.

- Desarrollar ayudas, materiales, adaptaciones curriculares que permitían un mejor proceso de enseñanza y aprendizaje.

- Implementar un programa de mejoramiento a docentes, especialmente la formación en postgrados, con énfasis en pedagogía, fundamentado en incentivos basados en conocimientos y habilidades.

- Desarrollar por parte de la administración municipal, especialmente a través de las juntas de acción comunal, programas de sensibilización de la comunidad en la importancia de la educación como eje central para mejorar las condiciones de vida de la población, lo cual permita el acompañamiento de la comunidad en el mejoramiento del proceso educativo. En este sentido, es imperioso que la secretaría de educación, las instituciones y

\footnotetext{
* Se puede ser feliz ejercitando tareas rigurosas, descubriendo el conocimiento y vinculándose con los demás a través de la solidaridad en condiciones difíciles.
} 
centros educativos creen vínculos con los padres de familia y busquen los mecanismos para informar sobre la oferta educativa a estas poblaciones.

- Implementar un plan de mejoramiento de infraestructura física y tecnológica necesaria y pertinente de acuerdo a los indicadores y estándares existentes al respecto, lo que permita una cantidad, calidad y disponibilidad de materiales educativos pertinentes, además de didácticas variadas, apropiadas y al alcance de los profesores, acorde con la diversidad de alumnos y contextos. Esto permita contar con dotación y ambientes de aprendizaje adecuados.

Se requieren políticas, del orden nacional, regional y municipal, destinadas a aumentar la cobertura educativa, especialmente en el ciclo preescolar 0 transición, pero mejorando calidad, así como medidas destinadas a mejorar el clima escolar, incorporando a estudiantes, docentes, directivos y padres de familias o acudientes, especialmente en la institución educativa ubicada en la zona objeto de estudio.

Es necesario por parte de la administración municipal, el diseño e implementación de estrategias y programas tendientes a reducir el nivel de violencia en la ciudad, especialmente, lograr reducir significativamente la alta tasa de homicidios, superior a la nacional y departamental, debido a que esto constituye un pésimo entorno social para los niños y jóvenes.

Sin lugar a dudas, existen otros factores y variables que pueden estar determinando la vulnerabilidad desde lo educativo y cultural, pero dado que la investigación aún se encuentra en desarrollo, falta procesar y analizar información que permita identificar dichos factores y variables, lo cual podrá hacerse una vez concluya la misma. 


\section{Referencias Bibliográficas \\ Fuentes Bibliográficas}

MARTÍNEZ Veiga, U. (1999). Pobreza, segregación y exclusión espacial: la vivienda de los inmigrantes extranjeros en España. Barcelona: Icaria editorial.

NUSSBAUM, M. C. (2012). Crear capacidades: propuesta para el desarrollo humano. Barcelona: Paidós.

NUSSBAUM, M. C. (2010). Sin Fines de Lucro: por qué la democracia necesita de las humanidades. Buenos Aires: Katz editores.

\section{Fuentes Cibernéticas}

BUSSO, Gustavo (20-21 de Junio de 2001). Vulnerabilidad social: nociones e implicaciones políticas para Latinoamérica a inicios del siglo XXI. Seminario Internacional "Las diferentes expresiones de la vulnerabilidad social en América Latina y el Caribe. Recuperado el 02 de Noviembre de 2012, de http://www.cepal.org/publicaciones/xml/3/8283/GBusso.pdf

BÁRCENA, A. (28-29 DE MAYO DE 2013). PANORAMA ECÓNOMICO Y SOCIAL DE AMÉRICA LATINA Y EL CARIBE. RECUPERADO EL 21 DE NOVIEMBRE DE 2014, HTTP://WWW.CEPAL.ORG/NOTICIAS/PAGINAS/8/33638/130528_PRESE NTACION_COMITE_PLENARIO-ABI-PANORAMA_ECONOMICO.PDF

GARCíA Serrano, C., Malo, M. A. \& Rodríguez Cabrero, G. (2000). Un intento de medición de la vulnerabilidad ante la exclusión social. Documento de trabajo 00-13 Unidad de Políticas Comparadas (CSIC). Recuperado el 26 de Mayo de 2011, de http://digital.csic.es/bitstream/10261/1517/1/dt-0013.pdf

KAZTMAN, R. (1999). Marco conceptual sobre activos, vulnerabilidad y estructura de oportunidades. Recuperado el 28 de Noviembre de 2014, de http://www.cepal.org/publicaciones/xml/6/10816/LC-R176.pdf

MOSER, C. O. N. (1998). Reassessing urban poverty reduction strategies: The asset vulnerability framework. World Development, 26(1), 1-19. Recuperado de

http://www.researchgate.net/publication/222872837_The_asset_vulnerability framework_Reassessing_urban_poverty_reduction_strategies

MOYA Mateus, D. M. (2013). Comportamiento de lesiones de causa externa, Colombia, 2013. Recuperado el 12 de Diciembre de 2014, de 
http://www.medicinalegal.gov.co/documents/10180/188820/FORENSIS+201 3+1-+lesiones+de+causa.pdf/8fde3e7c-f9e8-488a-8592-0916b81caaef

Organización de las Naciones Unidas para la Educación, la Ciencia y la Cultura UNESCO. (2003). Superar la exclusión mediante planteamientos integradores en la educación, un desafío \& una visión. Documento conceptual. Recuperado el 07 de Mayo de 2014, de http://unesdoc.unesco.org/images/0013/001347/134785s.pdf

Organización de las Naciones Unidas para la Educación, la Ciencia y la Cultura UNESCO. (27-29 de Septiembre de 2010). Atención y educación de la primera infancia. Informe regional. América Latina y el Caribe. Conferencia Mundial sobre Atención y Educación de la Primera Infancia Moscú, Federación de Rusia. Recuperado el 05 de Enero de 2015, de http://unesdoc.unesco.org/images/0018/001892/189212s.pdf

PIZARRO, R. (2001). La vulnerabilidad social y sus desafíos: una mirada desde América Latina. Recuperado el 10 de Octubre de 2012, de http://repositorio.cepal.org/bitstream/handle/11362/4762/S0102116_es.pdf? sequence $=1$

SUBIRATS, J., Gomá Carmona, R. \& Brugué Torruella, J. (2005). Análisis de los factores de exclusión social. Recuperado el 28 de Noviembre de 2014, de http://www.inau.gub.uy/biblioteca/exclusion_social.pdf

Universidad del Valle. Facultad de Salud. Escuela de Salud Pública. (2012). Análisis de la situación de salud en Guadalajara de Buga. Maestría en Epidemiología y Salud Pública, Curso Epidemiología. Recuperado el 12 de Diciembre de 2014, de http://www.guadalajaradebuga-valle.gov.co/apc-aafiles/37326536653334343839343565653263/asis-buga_2.pdf 